\title{
Socio-cultural Foundations of Caregiver Institutions: Lineage and Community Networks in Zimbabwe's Health Care System
}

\section{W.Z. Sadomba ${ }^{1}$, Lizzy Zinyemba ${ }^{2}$}

${ }^{1}$ Lecturer, School of Social Work, University of Zimbabwe, Zimbabwe

${ }^{2}$ Doctoral Candidate, School of Social Work, University of Zimbabwe, Zimbabwe

Volume 2, Number 1/2015

DOI prefix: 10.18034/ajhal

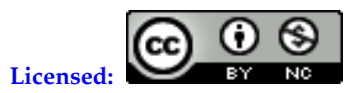

Source of Support: Nil

Conflict of Interest: None Declared

Email for correspondence:

lizzyzinyemba@gmail.com

\section{ABSTRACT}

This study sought to investigate factors that affect caregiver compliance to professional health advice with reference to children. An anthropological approach was used and clients were observed from mainstream health facilities to their homes to analyze the broader social structures, in familial settings, that influence decision making and final practices of the caregiver who visits the health centres. The study revealed a more complex pattern with a sophisticated cultural structure of caregivers who control and make decisions other than the person who visits the facility. Often this structure is unknown to mainstream health professionals with consequences on efficacy. In addition to the social structures is a powerful belief system that conditions the caregiver. This significantly compromises the advice by mainstream health professionals in a dual health care delivery system as Zimbabwe's. The study recommends that to improve on caregiver compliance mainstream health professionals need to know and engage this other invisible caregiver structure.

Key Words: Caregiver, children, mainstream health, belief system.

\section{INTRODUCTION}

Health as a biomedical issue is a long debate that has attracted extensive and intensive research in developing countries (Almeida, Molnar, Kawachi, Subramanian, 2009). Studies demand investigation of wider social and cultural factors for appropriate health interventions to be determined (Almeda et al 2009). For example institutions of care, perceptions of patients and medical staff, notions of satisfaction and efficacy of health systems all finally affect disease management and cure in a decisive way. It is now indisputable that health is but a part of a wider socio-cultural context yet studies 'rarely explore' these areas and how they affect referral (Crabstick 2009), satisfaction and subsequently, compliance. This realization has triggered more and more investigation of different cultural and religious beliefs, institutions and social structures which have largely been ignored by western practices. As observed elsewhere, the conception of health is in terms of "relational self, holism, and spiritual components" going beyond the individual to "incorporate other people and the environment especially kinship, the extended family and communalism" (Crabstick 2009:1343, Quintero GA. Lilliott E. and 
Wilging C (2007). These notions encapsulate perceptions of health and wellbeing in Africa particularly in Zimbabwe (Gage A.J. 1997; Chavhunduka G.L. 1998). This study draws close analogy with findings from studies of health perceptions and practices of indigenous Polynesians relating to "spirituality and religion in health" (Capstick et al. 2009). It also goes further to illustrate how the wider cosmology forms the fundamental basis of familial, kinship and community health care institutions, in relation to indigenous Zimbabweans. Social support networks contribute to health care (Almeida, et al 2009). The three studies that inform this study were all done during Zimbabwe's crisis of the past decade that started with war veterans led land occupations in 1998. By 2008, formal health institutions had been grounded. Articulation of and reliance on alternative systems were highest at this moment. In Africa, indigenous systems have a role in health, and there are a lot of studies about the different beliefs, practices and health seeking behaviors. There are few studies on the actual foundation of some of these beliefs, systems and practices. A deeper analysis shows that these systems, ways of life and institutions are entrenched in a given cosmology that is a much wider and deeper reflection of the universe. This cosmology determines not only institutions, but also a whole chain of health perceptions, which lead to the primary diagnosis, efficacious evaluation of different health systems and pathway decision-making. Although this study was carried in particular areas of Zimbabwe namely Mashonaland Provinces, Manic land and Masvingo provinces, findings have been generalized. Braun and Hammonds (2008) argue that the delineation of populations into 'ethnic' groups is as artificial as it is misleading. This becomes apparent when one tries to confine spirituality of indigenous Zimbabweans to a small group of communities. Zimbabwe was a regional centre of religion as it was an international power in commerce, industry and technology in the pre-colonial times (Bhila 1982; Mudenge 1988; Schimidt 1992). With inter-marriages, internal and outward migration and creation of colonial boundaries and resettlement of people, isolation does not make sense in such a subject like this one. Therefore, this paper refers to the culture of black Zimbabweans in general. This realisation has triggered more and more investigation of different cultural and religious beliefs, institutions and social structures which have largely been ignored by western practices. As observed elsewhere, the conception of health is in terms of "relational self, holism, and spiritual components" going beyond the individual to "incorporate other people and the environment especially kinship, the extended family and communalism" (Capstick 2009:1343, Quintero GA. Lilliott E. and Wilging C (2007). These notions encapsulate perceptions of health and wellbeing in Africa particularly in Zimbabwe (Gage A.J. 1997; Chavhunduka G.L. 1998). This study draws close analogy with findings from studies of health perceptions and practices of indigenous Polynesians relating to "spirituality and religion in health" (Capstick et al. 2009). It also goes further to illustrate how the wider cosmology forms the fundamental basis of familial, kinship and community health care institutions, in relation to indigenous Zimbabweans. Social support networks contribute to health care (Almeida, et al 2009). The three studies that inform this study were all done during Zimbabwe's crisis of the past decade that started with war veterans led land occupations in 1998. By 2008, formal health institutions had been grounded. Articulation of and reliance on alternative systems were highest at this moment. In Africa, indigenous systems have a role in health, and there are a lot of studies about the different beliefs, practices and health seeking behaviours. There are few studies on the actual foundation of some of these beliefs, systems and practices. A deeper analysis shows that these systems, ways of life and institutions are entrenched in a given cosmology that is a much wider and deeper reflection of the universe. This cosmology determines not only institutions, but also a whole chain of health perceptions, which lead to the primary diagnosis, efficacious evaluation of different health systems and pathway decision-making. Although this 
study was carried in particular areas of Zimbabwe namely Mashonaland Provinces, Manicland and Masvingo provinces, findings have been generalized. Braun and Hammonds (2008) argue that the delineation of populations into 'ethnic' groups is as artificial as it is misleading. This becomes apparent when one tries to confine spirituality of indigenous Zimbabweans to a small group of communities. Zimbabwe was a regional centre of religion as it was an international power in commerce, industry and technology in the pre-colonial times (Bhila 1982; Mudenge 1988; Schimidt 1992). With inter-marriages, internal and outward migration and creation of colonial boundaries and resettlement of people, isolation does not make sense in such a subject like this one. Therefore, this paper refers to the culture of black Zimbabweans in general.

\section{LITERATURE REVIEW}

The socio- cultural foundations of caregiver institutions are a rather complex phenomenon. There are five schools of thought that try to unveil the complexity surrounding the dynamics associated with health seeking behaviours. The phenomenon seems to differ from community to community. The independent variables that make the phenomenon differ ranges from women economic empowerment through education, community structures, kinship, traditional medicines and issues spirituality. Olarenwaju (2013), Mann, Bokosi, Sagala (2006), argue that if the people have economic freedom they have better chances of making decisions for themselves that affect their wellbeing. The assumption is that their attitudes and perceptions of maternal health will be changed by schooling. In his studies Olarenwaju (2013), concluded that the economic position of women and social status contribute drastically to their decision in the number of children they bear, when and where to give birth. Mann, Bokosi and Sangala (2006), demonstrated in their study that level of education has a strong correlation with uptake of conventional medicine. The more people are educated, the more they are less likely not to get involved in cultural practices and distinguish the difference between facts and myths. Hence, educated women make the decision to make use of conventional ante natal and post natal care services. The uptake of these services is higher where couples are educated and are aware of the benefits of the conventional ante and post natal care services, Awasu; Anyanwu;Okeleke ,(undated). Goshomi, (2009) and Munikwa, (2011) have noted that the level of assessing health risks and individual diagnosis of the health problem is influenced by level of education. This largely determines the choice of health care a person will opt for. Though Mwewa and Michelo, (2010) highlighted that there was an exaggeration of the relationship between education and health seeking behaviours, this could be accredited to a combination of factors like the women background. The second school of thought by scholars like Tuulonen 2005, Jansen 2006, Kadir , Fikfee, Khan and Sajan 2003, Mwewa and Michelo 2010, emphasizes the role that is played by the structures and systems in a society. These structures and systems control and define behavior in the communities in which people live. Jansen (2006), studied the decision making structures that surrounded child birth in a Ghanaian village. He argued that the social status of women is acquired through delivery. The more complicated deliveries the women experienced the more respect and authority to decide on other women health pathways during pregnancy in the community. In his study, he argued that the parents are so influential to the extent that they can influence a decision of a couple. Kadir, Fikfee, Khan and Sajan 2003 also stated the influential role of the mothers in law in their children's family matters concerning their wellbeing. Due to the social position that these elderly people hold in the society, they make decisions on where younger women should deliver, who should help the pregnant 
women during the delivery. They also make decisions on where to get assistance when the new born child is not feeling very well. The decision that the aged women make takes into cognizance the safety of the mother and the child. The social and economic constrains that might be prevailing are considered. Jansen (2006) The third line of thinking was elaborated by scholars like Mwewa and Michelo, 2010 Jansen 2006, Awasu, Anyanwu, Okeleke, (undated). They noted the supernatural world as having an influential role in the decisions that are made concerning maternal health. Jansen (2006) identified factors like spirituality that affect peoples decision making independence. In the event that the woman refutes the advice given by the significant people in the family, they had the power to curse or bless the younger people for not listening to their advice. These elder people were believed to have contact with the dead as they were the medium between the living and the dead in the communities. This is supported by studies Awasu, Anyanwu, Okeleke (undated) who persisted that some women preferred spiritual or traditional care, as in this institution that is where the cure for their cultural practices that are deemed crucial to their tribe can only be found.The fourth school of thought emphasizes the availability of traditional medicines that can only be found at the traditional healers as a factor that determines the decision of which service to use. Scholars like Jansen (2006) Mwewa and Michelo, (2010) in their studies in Zambia indicated that people preferred home deliveries because of the availability of some medicines that are not found in formal institutions for delivery. They also argued that in the event that one has a complication as a result of witchcraft, the family members might not be in a position to get appropriate assistance as they will be in an institution with different beliefs from theirs. These studies conclude that traditional beliefs, personal experiences, community perceptions and cultural practices have a significant impact on the decisions made in maternal health. The fifth school of thought by Frank (2011); Shimba (2010) emphasizes factors like the availability, acceptability, accessibility and affordability of health services as contributing factors to choice. Olarenwaju (2013) suggested that there were other factors that determined the choice of delivery as the household income and distance to the nearest health facility. The internal environment that prevails in the hospital and the services provided can either attract or deter the service users to alternative services available. Oluwatuyi (2010) described how neatness of the environment, attitudes of the health care providers, long waiting hours and the availability of drugs affect the decision to make use of either conventional medicine or traditional medicine.

\section{Research Methodology}

The researcher first observed and probed local knowledge and behavior in diagnosing child illnesses and the decision-making process of looking for relevant remedies. The researcher followed the route taken by the care-givers to manage illnesses and he studied local perceptions of the Mainstream health delivery system (hospitals, clinics, and VCWs, immunization programmes etc.) At each level the researcher considered such factors as belief, fear, trust, and willingness to comply. Local perceptions of compliance were examined. These variables aimed at getting a full understanding of the health care delivery processes, decision making and belief systems. The research involved a close observation of the people under study with 15 days a month spent in the study area. The study took an anthropological approach. This approach allowed an in-depth socio-cultural study of caregiver compliance. Besides physical and economic limitations, attitude and behavior of the health providers were considered important determinants of final 
compliance. The caregiver attitudes, behavior and the cultural disposition of the career were explored. Investigation of this type provided deeper understanding that could not be acquired through quantitative approaches. Behavior patterns, including compliance, are conditioned by social institutions, beliefs and values, which build the environment for making health choices and decisions. The research aimed at understanding the dynamics of these and the effect on compliance; and an anthropological approach was the most suitable. The study used various research methods as presented in the following sections.

\section{Focus Group Discussions (FGDs)}

The research undertook 10 Focus Group Discussions in the three geographical areas under study. This method was particularly suitable for this study in a number of ways. First, it is commonly used in the general forms of communication in the community. Mother caregivers always discuss in peer groups, focusing on the health of their children. Second, the flexibility of the method was appropriate for probing to achieve depth on specific topics. A cassette recorder was used to capture discussions allowing the researcher to concentrate on moderation and note taking. The FGDs were successful as they managed to give a broad overview of the health concepts, beliefs, attitudes, customs and dynamics. They were good at raising issues that needed further in-depth treatment through key informant interviews.

\section{Participant And Non-Participant Observation}

One of the methods used in data collection was observation. Participant observation was done at the hospital and at the chirembas facilities. At the hospital, the researcher went through the process of diagnosis and treatment. The researcher chose to have a dental problem attended to because that department had not been introduced to the research; and the health professionals did not know that they were under study. The researcher was also attended to by the chiremba who threw bones as diagnosis. For both cases, notes were scribbled soon after treatment. Non participant observation was used widely at the chirembas facilities and the community. The observations were followed by interviews with the professionals. Interviews were conducted with the caregivers before and after contact with the health professionals. The same process was done at the chirembas. Observation was done at the community level. Caregivers were followed up; and the researcher observed who by and how drugs were given to a child or patient. There was a careful observation of the location of drugs, as it was important to verify claims of who gave the treatment. The researcher also observed people who came to see the child. Their relationship to the child or the caregiver was noted to determine the pattern of actors who influence the caregiver. Comments on the illness and the advice they gave to the caregivers of the children were noted and scribbled. The observation method was useful in assessing caregiver understanding of health instructions and counsel. It was good in that it allowed the researcher to observe people in their environment thereby minimizing bias.

\section{UNSTRUCTURED INTERVIEWS}

In-depth, unstructured interviews were carried out at different levels of the research. At the hospital, the clinic and the chiremba's facility interviews were held with the caregivers before and after attending to the professionals. This method was used to probe on issues that arose from the FGDs and needed more examination. The researcher deliberately allowed the interviewee to talk at length in order to minimize framing of discussions. 
Points that required further interrogation were taken down in a note-book; and these were followed up with other questions. The method was suitable for the different people who participated in the research. It was easily flexible to suit the aged, women, health professionals and others because it did not follow any structure. Pilot interviews were carried out which helped to rearrange questions and the researcher familiarized with the order of questions. All interviews were cassette recorded.

\section{SAMPLING}

The geographical area of study was Zaka District in Masvingo Province in the South of Zimbabwe. The district is composed mostly of the Shona ethnic groups. Sampling was influenced by limited access to remote areas because parts of the district had been rendered inaccessible by Cyclone Elaine in March 2000. The researcher made a representative distribution of the study area, by studying communities in the north (Ndanga), at the centre (Gumbo, Jerera) and in the south (Bota Ward) of the district. In these geographical zones, the accessible areas were selected for study. The researcher walked long distances to more remote areas (Chivata Village, Muzhangiri, Chitukusa) which were inaccessible by car, in order to include the peripheral areas. In each area three levels were studied namely, (a) the community, (b) Mainstream health institutions (clinics and hospitals), (c) (chirembas) and Christian Faith Healers. At the hospital a record of people who came with children for any other purpose than baby clinic were interviewed before and after contact with the health professionals. The caregivers were observed as they went through the stages of treatment of the child. The stages included listening to peer conversations, observing mannerisms for subjective deduction of the presence or absence of fear, tension, anxiety, nervousness, calmness and so on. These deductions were carefully matched with interview responses and observations caregiver/professional interaction. Some of the interviewed cases were followed-up for observation at their homes. The selection of cases was based on the nature of the disease and caregiver network identified during the interview at the health facility. Health records from the OutPatients (OPD) and Rehabilitation Departments were used to randomly select cases for study, balancing compliant and non-compliant cases categorized by gender that were visited in their homes. At the clinics, the researcher identified caregivers in the waiting area. Mother caregivers were classified according to the disease or health problem of the child, selecting both long term problems (e.g. cerebral palsy, T.B.) and short term ones (e.g. malaria). At the Indigenous Health Professionals (chirembas) and Christian Faith Healers almost all cases of caregivers were interviewed. Two male chirembas, one female chiremba and one female Faith Healer were observed for several weeks each. Eight Mainstream health professionals were interviewed; and four of them were closely observed at work for several weeks, in the hospital. A more detailed survey was done at community level in the south (Bota Ward) than both the central and the northern parts of the district. This was so because accessibility to facilities in the north and central areas of the district is much better than the south. Influence of the hospitals is much lesser in the peripheral south than the north and the centre. Stratified sampling technique was used because a group of caregivers, for under fives, was the focus of this study. However, there were exceptions. Systematic sampling was carried out in combination of other sampling techniques at the community level. With the help of the VCWs, mothers of under fives who lived with their mothers-in-law or their mothers were studied. Another systematic selection was of 
indigenous midwives, chirembas and Faith Healers, who were identified at local levels by their skills and professions.

\section{Findings AND Discussions}

This part presents the results and discussions thereof. For ease of reference, each finding is immediately followed by the relevant discussion although there is a clear separation of the two. The main findings are boxed to make conspicuous. These are mostly excerpts from informants' responses. The first section deals with the being of a infant. The second covers pregnancy and is followed by the fourth section with breastfeeding and child upbringing. Section five is about the caregiver community and its dynamics. Section six contains illness management and health seeking behavior and lastly section seven deals with the concept of health and perceptions of treatment. Studies in Sub Saharan Africa show that there are two health delivery systems that the majority of the people refer to for different purposes. The one is indigenous (African) and the other is mainstream health care delivery system. There is also another widely spreading group of Faith Healers in Zimbabwe. The first two and major systems compete in both child care and illness management, setting a highly contested zone of choice during the process of child upbringing and disease management. What do people perceive about these health care systems and how do these systems influence the referral process? What is the nature of decision-making and how is power negotiated amongst various players before a particular system is pursued, pursued, changed or mixed? The findings of this study attempt to answer some of these questions.

\section{The Child in the Wider Cosmology}

An interview with a young mother $(\mathrm{M})$ who had come to the clinic with her ten day old baby that had a skin rash reflected a wider notion of a child beyond the social and biological attributes. When interrogated $\mathrm{M}$ - a teacher by profession - her beliefs about African medicines she said she did not believe in that as she only trusted western medicines. When I asked what she would do if the child got serious she said she and her husband would inform the husband's parents - i.e. child's agnatic grandparents - to participate in the decision of what next to do. This was when she revealed that already the grandmother G - husband's mother - had come to treat the fontanel of the child by giving it porridge with African medicine, mufti. I probed M's understanding about exclusive breastfeeding and she replied, 'It means that a child should be given breast-milk any time it desires so there is no need for supplementary feeding'. The question was why then did she allow the child to feed with mufti porridge? $M$ argued that she did not resist treatments by $G$ even if it contradicted her beliefs and mainstream ideas because the treatment is according to the customs and traditions of the child's clan (nekuti izvi ndezvekurudzi kwavo). Ultimately $\mathrm{M}$ was bound and dependent on health rituals that were followed by the agnatic family. She continued further to say that if they (agnatic family) decided to take the African path contrary to her beliefs, she would not resist the decision as long as they directly treated the child. Many Zimbabweans, particularly groups now considered Shona are partrilineal. Customs of these people consider a kid as belonging to the family of the father. But more than just acquiring the family name the child's spiritual being is also determined by this social identity. The child (mwana) is more than a biological offspring but is positioned it in a long continuum from the departed ancestors, the living dead to the yet unborn. To connect this child with this world of the living dead, there are many rituals, ceremonies and practices that are followed even today 
which many, despite western influence, still believe in or adhere to. For example procreation itself is not considered just a physical sexual activity but one that has to invoke the participation of the living dead. This involves a branch of praise poetry called madanha emugudza (recited by the woman) and zvirevereve zvemugudza (recited by the man). Essentially these are poems during the sexual act calling upon the living dead. When a child is born there are many more rituals performed uniquely by and for the agnatic family members. These include the health rituals called kurapira, burial of the umbilical cord and others. The child is just; but one individual in this long intergenerational continuum and is born with rights and obligations from this social setting. Institutions, values, customs, family structures and the body politic all function to express, sustain and propagate this being of the child. Parenthood and childhood are defined to reflect and abide by this cosmological relationship. This deep meaning and complex perception of the child has wide implications on roles, attitudes and behaviour that ultimately affect health practices and perceptions. When nurses in clinics and the district hospital were interviewed, they expressed the same views as M, saying, they followed the health customs as outlined by the agnatic family of the child whether or not these traditions contradicted principles of mainstream health care. They emphasised that they submitted to the traditional structures in deciding on their children rather than just the perceived efficacy of the system. This understanding of the being of the child also affects the duration of 'childhood'. Two of the observed cases involved 'children' who were under the care of their mothers. However, these 'children' were adults in their thirties. Both of them had their children. One was suffering from puerperal psychosis; and the other was paralyzed from a stroke. Diseases or conditions can be interpreted to be caused by factors that are not biological but spiritual. In this case care and health seeking has to be determined by the family. Because many Zimbabwean communities are exogamous, the wife has to return to her family for such care and treatment. It is presumed that only the family knows how to communicate with its living dead to solve the problem. Decision making in the management of illness or general upbringing of the child can be taken at higher levels, than the biological parents. ill health management of certain conditions and diseases might still require that the patient be treated as a child; and the 'parents' take responsibility and authority of care even if the child is a great grandparent. In many cases, grandparents have superior influence than the biological parents of the child, and this has to be appreciated if compliance in health is to improve.

\section{The Caregiver Community and ITS Dynamics}

This section presents individuals who are critical to traditional health institutions in the 'Shona' people of Zimbabwe. Individuals involved in giving care at one point or the other are many. They form an intricate network of the caregiver community. The main characters who influence decision-making on health care are the father, mother, mbuya/grandmot her (mother's mother), vamwene (mother-in-law), great grandmother (father's grandmother) and other family members.

\section{Father}

The father of the child has wide ranging powers that override other caregivers in the network or community of caregivers. These powers mainly stem from his lineage to which the child or individual belongs. The child belongs to the father; and its spirit will join the living dead of the father when it dies. However, his powers are subjected to checks and 
balances because the father is a child as well, in the eyes of his parents. He unconditionally submits to them in times of crucial decisions about illnesses. Lack of knowledge of the father about child disease and the social relation with his parents leaves him in a position that he would still pay attention to other opinions like that of his own mother, his grandmother or his wife. Amongst all these people, his mother is the most influential and authoritative to him. In two observed cases, each father decided to send the sick child, who was under the care of its mother, to his (father's) mother for her to take over care roles when the condition of the child was worsening. In both cases, the vamwene assumed the role of principal caregiver and the mothers of the two children were only secondary caregivers.

\section{Mother}

The mother of the child has the highest access to the child; but highly limited authority to make decisions. She is responsible for the general upbringing of the child and looks after the child on a day to day basis. However, a lot of what she does in child care and illness management is based on specific teachings about child care and poor health management which she goes through during the kusungira ritual. This is a process of giving birth for the first time. The pregnant wife is surrendered (about 2 months before delivery) to her family for post and part of the anti-natal care during which time the wife undergoes intensive education on birth, childcare, child illness management and the customs relating to these. She is conditioned to submit to the authority of the vamwene, her husband and other members of the extended family. As discussed below in relation to father's mother, women in Shona play critical spiritual functions that impact on the general life of the individual. A Shona saying that wraps it all is "Midzimu yamai yadambura mbereko"; which can be translated as "the living dead on the mother's side have broken straps of the carrying towel [for the child to drop lifeless]." This expression is used when one gets in grave danger with slim chances of survival. As such traditional spirituality of Zimbabweans does not give a monopoly of the agnatic living dead over the offspring but recognises the maternal living dead even more.

\section{Father's Mother}

Besides the child's mother, the agnatic grandmother has the most access to the child. When a child is ill the role of the agnatic grandmother shifts from just being an "advisor" to that of managing illness and providing care as a mother. In one FGD mothers emphasised that their in-laws (vamwene) even move to sleep in the same hut with the sick child and take turns with the mothers to look after the child. In addition, a great benefit is derived from the long experience and knowledge of child illnesses of the vamwene. One woman in the FGD said the following "The vamwene, playing the traditional role, strictly examines the illness of the child to satisfy themselves about the exact illness of the child. At times, we end up not going to the hospital at all because vamwene knows how to handle the condition. They do what they know there and then even though they are not spirit mediums or medicine specialists themselves. For example, they handle cases like (nhova) fontanel problems which used to be recognized as chipande; that's how the vamwene function. They know a variety of child illnesses, because they have seen them before and can recognise them where they see them again. One of the most important processes in traditional marriage is that the living dead of both are conjured up to take their spiritual roles on the wellbeing of the individual. The bride's maternal living dead 
are invoked through a beast paid to her mother known as mombe yehumai; which is a sacred animal according to the traditional beliefs in Zimbabwe; and marriage would be problematic if this is not paid. The function of the cow is to invite the maternal living dead to take their spiritual role of protecting marriage and the life of the children born by their daughter. The vamwene therefore, has a double function. On one hand the living dead of her family play a greater role to protect the child's father and the father might dare not anger his mother because he would be punished by kutanda botso. The punishment involves going around with a begging bowl for food to eat and also for millet enough to brew beer to appease the mother's spirit. This is one of the most feared punishments by any Zimbabwean. On the other hand, vamwene acquires vast paediatric knowledge including spiritual diseases and conditions.

\section{Mother's Mother}

Mothers expressed that their mothers - i.e. child's maternal grandmother - educate them about child upbringing. This socialization process involves exposing the daughter to a number of taboos, rituals and customs relating to lineage structures and spirituality and to practical health issues relating to pregnancy and child-birth. During the kusungira - a prenatal process of care done by a woman's mother who is responsible for preparing masuwo medicines that dilate the birth canal in preparation for child-birth. If the woman's mother is not familiar with these medicines, they are responsible for referring the pregnant daughter to specialized midwives who do this. Although mother caregivers admitted that the common thing now is to go to clinics for antenatal care (ANC) and delivery, they argued that kusungira is done in combination with this ANC. It is also during the kusungira period that the caregiver is trained the medicines for kurapira. These are medicines to protect the child from evil spirits or prevent problems associated with the fontanel. In an FGD with principal (mothers) and secondary (grandmothers) caregivers the former said that they had been given traditional herbs of kurapira and were taught how to administer them by their mothers during the first births when they were under kusungira prenatal care. This knowledge was applied to subsequent children and they said they were still going to use them on other subsequent children. These traditional herbs are administered irrespective of following exclusive breastfeeding principles. It is important to note here that the spiritual position of mother's mother is no longer that strong to the sick grandchild as the living dead of her (mother's) father are. The agnatic spirits of the mother are the ones that have the power on the grandchild. As a result, the mother's role is mainly biomedical to the grandchild. However, her prenatal and antenatal care position to the pregnant daughter is different. At this point her position is both spiritual and practical health care. The mother's living dead are the ones who protect the daughter's spiritual life and if they should "cut the straps of [her] carrying bag" then she would die of complications. So the kusungira is also a process of communion by the mother of a pregnant woman with the living dead of the maternal spirits. It is these multiple roles cutting across spiritual and social structures that shape a complex matrix traditional health institutions and pattern of caregiver community.

\section{Great-Grandmother (Mother of Father's Father)}

The father's grandmother is part of the father's extended family and usually lives with the youngest uncle (babamunini) of the father. It is common that the grandmother of the father (mother of father's father) is still alive. In one FGD the discussion centres on the 
interaction between this great-grandmother and a mother of a sick child and vamwene (father's mother). It was explained that the nature of communication between great grandmother and mother of the sick child differs from the dialogue between her (mother) and vamwene. The former communication is relaxed (haazi munyarikani) and can be playful. The grandson (father of a sick child) can talk freely about sexuality and other topics that he could never discuss with his mother or father. The trio (great grandmother, mother and father) confide in each other about family and sexual issues. The grandson is even considered to be 'husband' to the grandmother, who is supposed to take care of her. This relationship is mainly social and does not have a spiritual effect. Because of its relaxed nature the relationship is useful in dealing with stress and its intricate causes which the husband and wife could not easily talk to anyone about. If there are sexual problems the two freely talk to the great grandmother. Some child illnesses require abstinence from sex by the parents or anyone who visits to see a sick child. Failure to observe such taboos is believed to cause death of the child. It is usually the great grandmother who monitors behaviour of the two and tells them not to have sex during this period.

\section{ELDERLy COMMUNITY WOMEN}

The community also plays a significant role in giving care and affects the rate of compliance. Elderly women have an important influence on the decision of young mothers. In Shona customs seniority of age is considered essential in determining the status that is derived from the spiritual hierarchy of the people. Seniority of spirits in the world of the living dead is by age ranking of their mortals before departing to the spirit world. There is also a social dimension to this, which is that Shona people age to be proportionate to the wisdom; and the older one gets, the more the respect accorded. The role of elderly people in the community in health care was highlighted by a young mother (late thirties) who was caring for a child with cerebral palsy who was observed and interviewed for several days. She explained that she was encouraged to go for physiotherapy at the hospital by an elderly woman (mid sixties) who lived in the nearby village. The old woman's grandchild also suffered from a cerebral palsy condition and felt obliged to share her knowledge and experience with the young mother. She (old lady) assured the young mother that the condition of her child could be greatly improved if she (young mother) worked hard and complied with physiotherapy instructions. The young mother at first refused to follow the advice of because previously hospital staff had illtreated her. The old woman made repeated visits and later invited the young mother to see her own (old female's) grandchild with the same condition. Only after this ocular proof did the young mother start to comply and at the time of the research she had been consistent for more than ten years. She even had erected wooden rails for exercise of the child. Explaining what finally convinced the young woman to comply pointed out to that senior age was the contributory factor when the old woman repeated her visit. She indicated that it was considered bad behavior to ignore the advice of elders. She said that rejection of such advice would cause the elderly to leave one alone in subsequent cases. Such 'isolation' is a form of social punishment. The young mother admitted that even if she would not have accepted to go to and see the grandchild of the old woman if it had been a young mother who had approached her. It is not easy to convince people about conditions like cerebral palsy that are associated with spiritual punishment. Other factors 
within the customs and beliefs about age seniority might are therefore, more useful as in this case. Senior citizens in the community are highly helpful in the caregiver network.

\section{The Caregiver Community and its Dynamics: A Bird's Eye View}

The concept of caregiver in rural Zimbabwe has been limited to individuals who directly look after a sick child and in most cases these are the mothers. Mothers are usually the people who bring the sick child to the hospital or clinic. However considering that the network of caregivers is much wider than the individual, it is important to understand the dynamics of care that result from multiple roles and interactions between and amongst different people. Widening the concept of care will cause a general classification of caregivers based on decision making power, access to the sick, social status and spiritual position. Caregivers are classified as primary, secondary and tertiary caregivers depending on their relative effect on final compliance and decision making relating to the helpless sick. As discussed below, the status of caregiver is not immutable but keeps changing in time and space influenced by society's world outlook and spirituality, age, gender, knowledge and social standing. It is a much more complex pattern than the physical appearance of an individual with the sick child. Failure of health authorities to appreciate the complex pattern results in compromised efficacy of the health system as people who make final decisions are excluded from participating in the process of diagnosis and treatment. For example, in one of the observed cases at the hospital, the grandmother accompanied the mother, whose child was suffering from chronic diarrhoea to the hospital. There the two caregivers were separated, excluding the grandmother from the process taking place in consulting and treatment rooms. The doctor who could have attended to the child was not there and the nurse gave two options to the mother caregiver as follows: (a) to get the child admitted so that the doctor would see him during ward rounds or (b) to get some medicine prescribed by a nurse, go home and return two days when the doctor would be available. The mother caregiver could not decide and had to consult the accompanying grandmother, her vamwene who had decision making powers at this stage. The vamwene rejected both options and instead instructed the mother to take the child with them home. Instructions were given to the mother only who was presumed to be the sole caregiver. However, contrary to the belief of the health providers, the grandmother was the primary caregiver at this stage; and the mother was only playing a secondary part. In complete contrast, all traditional medical practitioners [chirembas] and faith healers, owing to their understanding of the culture, always first identified the primary caregiver before attending to the sick. If this primary caregiver were absent, it could even result in non-treatment. They emphasised that they would not attend to patients without the participation of the primary caregivers or at least they needed their blessings, except in extreme emergency cases. The woman suffering from puerperal psychosis could not have been attended to if she had, for example, come with the husband alone without representation of her agnatic family members. Final treatment of a helpless sick individual is dependent on the caregiver; and traditional medical practitioners and faith healers are well aware of this thereby getting higher cooperation and ultimately more efficacious. A caregiver is not simply a person who comes carrying the baby to the institution. It is not necessarily the mother of a child who brings the child to the health centre. Behind the person is a complex hierarchy of individuals with various levels of authority and playing multitude of roles and sharing various responsibilities. They constitute a sophisticated caregiver community network. The functions and power of individuals are negotiated and constantly shifting, giving a social dynamic with seriously implications of the whole system. These are the people who finally 
determine final compliance if the sick is helpless. An analysis of social dynamics revealed that the role, authority and contact with the child determine the status of the caregiver. A primary caregiver is one on whom all the three factors converge at a given time. At any stage in disease management the higher the spiritual position, level of authority and responsibility, age and social status, the more primary the caregiver becomes in relation to other players. Often in managing chronic illnesses the mother has the highest access to the child, but very little authority whereas the father has more authority but very little contact with the child. Other family members like the agnatic grandmother have high access, more responsibilities and authority and are generally the actual caregivers who choose what action to be taken. Health professionals need to be mindful of the 'invisible' agents of care because they determine final compliance. From the observation, the Mainstream health professionals are not. For example, a 12 year child who brought a sibling of 7 years to the clinic for treatment of an infectious disease (chicken pox), was attended without any further inquiry of finding out who, where was, and why not the principal caregiver had not accompanied the young girl. The researcher could not follow-up this case to monitor what transpired after leaving the clinic. Observing Mainstream-trained health professionals and indigenous professionals (chirembas and Christian Faith Healers), it was clear that there are wide differences in the way caregivers are viewed. On one hand, nurses and doctors in Mainstream health systems do not consider the dynamics of the caregiver institutions. Little consideration is accorded to the participation of the principal caregiver (who might be covert) in the treatment of a patient. On the other, indigenous health professionals understand the extended family set-up and its dynamics and these customs are assimilated into their practices. Factors that determine illness management and health-seeking behaviour of caregivers are: the conclusion of preliminary diagnosis, decision of the principal caregiver, influence of other caregivers, severity of the disease, comfort of health delivery system, care education by responsible family institutions, communication and costs.

\section{Health Seeking Pathways Decisions}

The mother, owing to her access to the child, is expected to be the first one to know about the child's illness. However, interviews and FGDs revealed that most less-obvious illnesses are diagnosed first by the vamwene. Access to, or contact with the child raises opportunities to observe signs of disease. Access is improved because of the custom that the grandmother always has a duty to mind the grand children. When the mother signs of disease, usually judged by fever or high temperature, body malaise and poor appetite, the first person she tells is the father of the child, her husband if he is present. If he is not there, she tells the vamwene directly. If the vamwene discovers the condition first (which often happens), she informs the daughter-in-law (mother of the child) and advises on action to take. When the mother advises the father of the child, the intention is usually for decision-making or to solicit for material and financial support. The two engage in a preliminary diagnosis and decide where to go. They regularly strive to reach an agreement, but the husband has the final say. One respondent was asked what she would do if no agreement was struck in the negotiation; and she said that she would first follow what the father of the child says and then later suggest changing treatment if there is no marked improvement. A Mainstream-trained health professional argued that she would not antagonise her husband even if she knew that the decision was contrary to her medical knowledge, "because I am an African, despite my training and profession". In another case the father instructed that African medicines had to be used exclusively after changing 
from the mainstream health delivery system. Because the mother knew that he had decision making powers, she did not contradict but used her access to the child to mix treatment without the knowledge of the father. However, when the mother informs the grandmother of the child about signs of a disease she does for two reasons. The first reason is to give the task for initial diagnosis and secondly to give the grandmother the power to decide. Depending on the nature of the condition, the grandmother assists in the diagnosis and confirms the preliminary diagnosis. If the mother is not familiar with the condition or disease, the grandmother diagnoses and usually educates the mother about the condition. If the condition or disease is minor, the grandmother usually just confirms the decision taken and allows the woman to implement her decision. The grandmother also decides on the health care delivery system to follow; and at times determines her role in the chosen pathway. If the preliminary diagnosis results in classifying the cause of the illness as spiritual the child is taken to the chiremba or faith healer straight. Whenever a child is taken to the indigenous health professionals, the mother never goes alone but always has to be accompanied by one or some of the agnatic relatives of the child especially when she is still young. Chirembas cited the uncles (babamukuru, babamudiki i.e. father's brothers) as the people who accompany the mother and the child if the father is absent. During observation, a puerperal psychosis patient was accompanied by a brother, a wife, a mother, and her young sister. The father, a paraplegic, could not accompany come but was adequately represented, and the faith healer attended to the patient. Although there are two health delivery systems in Zimbabwe, namely: the mainstream health system and indigenous health delivery system there is general denigration of indigenous institutions by personnel of the mainstream system. This research confirms findings of other researchers who expressed general dissatisfaction by patients in relation to mainstream professional services. Patients were insulted for visiting traditional practioners or faith healers (Chavunduka's, 1998:8); and nurses were described as "hardened and indifferent" towards patients, "haranguing and insulting" pregnant mothers. An expatriate who had worked as the District Medical Officer for Zaka confirmed this behavior by mainstream health staff, in an interview. Denigration of indigenous systems of health by mainstream professionals throws people in the horns of a dilemma. People's perception of health and their behavior reflect flexibility and calculated choices of the various systems available to them. They freely choose and mix them and continuously evaluate treatment or healing throughout. All this depends on their preliminary diagnosis and the expectations of the caregiver network. Such diagnosis by caregivers needs to be taken seriously, as parents are able to provide valid assessment of their child and awareness of this has led to substantive changes in health care delivery system elsewhere (Venter, 1997). The indigenous health care system has evolved out of and as part of the local culture. As such, it could not divorce itself from other operating norms, beliefs and philosophy of life. It, therefore reflects the institutions, power dynamics and communication systems of the society in general. This appears to be the reason indigenous health systems have withstood the test of time. The indigenous health professionals pay attention to family dynamics, and they appreciate the struggles between and amongst individuals. Even more so their system of operation takes these issues into account, and they assimilate them. For example, the makumbi is a paramedical person whose psycho-social function it is to relax the patient or caregiver, give the necessary support and ease communication between the chiremba and the patient or caregiver. Such a function could be regarded in the training of health professionals. The findings of this research show that mainstream health delivery system is operating parallel to both the indigenous health system and worse still, parallel to the cultural disposition of the people. The community expressed the feeling that hospitals and clinics tend to approach health from a pure business angle. 


\section{Caregiver Perceptions of Mainstream Health Care System}

Choice between indigenous and the mainstream systems depends on perceived efficacy of the one against the other. Discussants in FGDs said that mainstream institutions have superior facilities because there is all weather shelter. They also pointed out that the personnel had a high standard of hygiene. Interviewees and FGD discussants said that the clinics and hospital staff however are "rude", "moody", "insensitive" and "impatient". Observations of interactions confirmed this perception of the respondents. When talking to the health professionals, caregivers were pensive and expressed fear. The manner of communication changed when they talked with health staff than when they discussed among themselves while waiting for services. An observed case confirmed this relationship between the two. A mother caregiver who brought her asthmatic child to the hospital said, in a pre-contact interview (i.e. held before the caregiver interacted with professional) that she had questions to ask the health providers during the consultation. The child had been asthmatic for more than six years and she wanted to know when to stop medication. Contrary to the desire that she expressed in the pre-contact interview, the mother did not ask anything However, when we set for a post-contact interview the caregiver asked this researcher straightaway. She asked whether she could use the prescribed tablets continuously even if the asthmatic attack had subsided or she would stop medication and resume only when another attack occurred. The researcher invited her to go back to the health professionals who gave her the medicines hoping to further make observations about interaction between the two. She refused to go back and instead went home showing clear signs of discomfort. This was a vital question which she probably had had for several years. A Mainstream-trained health professional again confirmed this view. She said that clients at the hospitals are less free than those at the clinics and she attributed this to the fact that since clinics are more localised caregivers end up familiar with the staff and they interact a lot with them outside work situations. She however said that caregivers are not generally free at the facilities. Bassett et al (1997) who compared rural and urban health care in Zimbabwe saw argued that the situation was worse in urban areas which might be caused by even more remote interaction between professional and the community. In comparison caregivers said that they are freer at the indigenous health care facilities than at the mainstream facilities. In an interview with a key informant it was said that chirembas are free to be asked questions for clarification but the professionals at the hospitals and clinics did not accommodate questions. She said that professionals consider asking as an intention to despise or underrate him/her (the professional). All discussants of focus group discussions confirmed this view and clarified that this invokes fear about mainstream health facilities. Both interviewees and discussants said that chirembas communicate well with their clients and they are humble.

\section{Discussion on Caregiver Perceptions}

There is no doubt that the mainstream health facilities have a high number of patients at a given time compared to a chiremba but the statistics are not clear if numbers at all traditional practitioners in the study area were aggregated. Higher numbers at the mainstream centre's could be because of the nature of distribution of the facilities as compared to the indigenous institutions. The Chairman of Zimbabwe National Healers Association (ZINATHA), in Zaka estimated the number of registered traditional practitioners (chirembas) to be more than 250. This number excluded unregistered and other knowledgeable individuals as old women who are consulted about child illnesses. This spread thinly clients of indigenous practitioners as compared to the eight clinics and 
two hospitals in the district. Pressure at mainstream facilities was a major cause for poor communication by the staff, to some (Bassett et al 1997:1849). There is no time for lengthy greetings and other customary mannerisms resulting in ultimate reduction for compliance by caregivers or choosing the system as the last resort. It is suggested that training of health providers should include socio-cultural studies which encompass people's worldoutlook, institutions of care as well as specific health beliefs and customs. Communication for outreach programmes, need to be enhanced. There is need to explain to the clients either as communities or as individual health seekers the limitations of the facilities and to design more interactive programmes around catchment areas of facilities.

\section{CONCLUSION}

This paper argues the notions of health are wider than is recognized by mainstream health biomedical professionals. However, in crisis situations people not only tend to rely on cultural capital of health i.e. cosmology, religion, kinship, family and community networks of care but they also articulate these resources more keenly. A study cosmologic foundation of health care networks reveals a sophisticated and robust system that has survived the test of time and that has to potential to support health delivery under crisis. Socio-cultural factors determine behavior of the caregiver. In a Zimbabwe there are visible and invisible caregivers both of which need to be assimilated in the health care delivery system without discrimination. The dynamics of kinship, lineage and extended family are such that care giving is a contested terrain, with decision making power, authority and responsibility shifting in time and space. Spirituality does not only affect the patient psychological but determines the nature of health institutions defines general roles and imposes structures which share limited decision making power. A complex system exists. From diagnosis to cure, a variety of actors are involved, many of whom are never seen at the mainstream health facility but mainstream health professionals are either completely unaware of these or they deliberately ignore them. This is different from indigenous health systems which have developed out of this cultural setting and continue to operate within in it. The practitioners comprehend well the philosophy, attitudes, practices and institutions involved in the health of their clients. Their continued adherence to these cultural norms is one of the reasons why they have managed to survive against all odds and mainstream health could learn a lot from this practice.

\section{REFERENCES}

Almeida J. Molnar B.E. Kawachi I. Subramanian S.V. (2009). "Ethnicity and natitivity status as determinants of perceived social support:Testing the concept of familism." Social Science and Medicine.

Awasu V,O. Anyanwu, E, B. Okeleke V undated Determinants of antenatal care services utilization in Emevor village Nigeria. Benin Journal of post graduate Medicine. Accessed 23.02.2014 www.learning matters.co.

Bassett MT, Bijmakers L. And Sanders D.M., 1997, Professionalism, Patient Satisfaction and Quality of Health Care: Experience during Zimbabwe's Structural Adjustment Programme, Social Science and Medicine Vol. 45, No.12 pp 1845-1852.

Bhila H.H.K. (1982). Trade and Politics in a Shona Kingdom: The Manyika and their African and Portuguese Neighbours 1575 - 1902. Harare, Longman.

Chavunduka G.L. (1998), The Professionalisation of Traditional Medicine in Zimbabwe p8, Harare. Chigwedere A. (1985). The Karanga Empire Harare, Books for Africa.

Chavunduka G.L. (1998), The Professionalization of Traditional Medicine in Zimbabwe p8, Harare, ZINATHA.

Jansen I. 2006 Decision making in child birth : the influence of traditional structures in a Ghanaian village accessed 16. 012012 http:/ / inten-ationalnursing.reviewpdf 
Kadir , Fikfee, Khan and Sajan 2003, Do mothers in law matter ? family dynamics an fertility decision making in urban squatter settlements of Karachi Pakistan. Abstract http:/ / biosocdo:10:1017/s002cambridgeuniversitypress

Khan M. Education and Health Status of Child Workers of Dhaka City Global Disclosure of Economics and Business. 2014;3(2):16-23.

Mann G, Bokosi M, Sangala W, 2006, why are pregnant women dying? An equity analysis of maternal mortality in Malawi. Malawi medical journal 18 (1) accessed 10.10. 2012 elearning

Mudenge S.I.G. (1988). A Political History of Munhumutapa c 1400-1902. Harare, Zimbabwe Publishing House. Mwewa D.Michelo C. 2010 Factors associated with home deliveries in a low in come rural setting - observations from Nchelenge district, Zambia. Medical journal of Zambia Vol 37 No 4 accessed 22.10.2013 elearning.

Olarenwaju O.F. 2013 women empowerment as a determinant of investments in children in selected rural communities in Nigeria. Multidisciplinary Journal, Ethopia Vol. 7 (4) accessed on 12.01.2014 on http:/ /dxdoi.org/104314/afrrev.7i4.9

Oluwatuyi O, 2010 Health seeking behavior among the rural dwellers in Ekiti State, Nigeria. An International Multi -Disciplinary Journal , Ethopia Vol 4 (2) online journal

Quintero GA. Lilliott E. and Wilging C. (2007). "Substance Abuse Treatment Provider Views of "Culture": Implications of Behavioural Health Care in Rural Settings." Qualitative Health Research(17).

Rahman MM, Chowdhury S. Does Micro Health Insurance Solve the Problem of Providing Accessible Healthcare to the Poor? Evidence from Niramoy Project, Bangladesh Global Disclosure of Economics and Business. 2014;3(2):7-15.

Sadomba WZ., 1999, The Impact of Settler Colonisation on Indigenous Agricultural Knowledge of Zimbabwe: Fusion, confusion or negation? MSc. Thesis, Wageningen University, Management of Agricultural Knowledge Systems.

Sadomba WZ., 2000, Factors affecting Caregiver compliance in Zaka District of Zimbabwe, UNICEF Harare and New York.

Sadomba WZ., 2008, War Veterans in Zimbabwe's Land Occupations: Complexities of a liberation movement in an African post-settler society, Wageningen University PhD thesis, Technology and Agrarian Development.

Schimdt E. (1992). Peasants, Traders and Wives: Shona women in the history of Zimbabwe 1870-1939. Harare, Baobab.

Venter A., Caregiver' expectations of services at Baragwanath Hospital, Soweto and their understanding of the child's disability, Developmental Medicine \& Child Neurology 1997, 39: 815-820

Zahan N. 2014. Factors Influencing Women's Reproductive Health ABC Journal of Advanced Research, 3, 38-46.

This article is is licensed under a Creative Commons Attribution-NonCommercial 4.0 International License. Attribution-NonCommercial (CC BY-NC) license lets others remix, tweak, and build upon work non-commercially, and although the new works must also acknowledge \& be non-commercial.

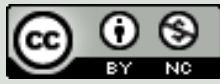

How to Cite: Sadomba WZ and Zinyemba L. 2014. Socio-cultural Foundations of Caregiver Institutions: Lineage and Community Networks in Zimbabwe's Health Care System Asian Journal of Humanity, Art and Literature, 2, 43-60. 


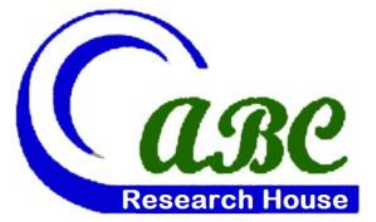

- Off Pantai Dalam, Kuala Lampur, Malaysia

- Road \# 4, Shyamoli, Dhaka-1207, Bangladesh

- 3900 Woodhue Place, Alexandria, VA 22309, USA

www.abcreorg.weebly.com / www.abcjournals.net

Asian Business Consortium (ABC) is a multi-disciplinary research, training, publishing, digital library supporting and service house. Though founded in 2010 as the Business and Computing organization of Asia, it was reconstituted as the ABC in 2011. It has been working for creating and nurturing talents in USA, Malaysia and Bangladesh since its inception. The objectives of consortium are solely centered round the welfare and humane attitude of the founders who enthusiastically took up this noble cause and materialized it with a view to promote research and educational activities for the encouragement of scholars to develop their knowledge, to publish their analysis oriented scientific researches in international Journals, books, the task of organizing workshops, seminars, conferences, training, personality development programs and allied services.

In addition to research activities, $\mathrm{ABC}$ provides a good number of scholarships to the poor and meritorious students at various levels of education throughout the world. It plays an important role in the field of research by funding research projects and publishing the research papers. This consortium will unquestionably become the mouth-piece of the dark horses and unacknowledged scholar whose endowed and commendable contributions shall be provided an outlet keeping in mind the greater good of the larger society of the world.

$A B C$ runs the following international referred journals for creating a platform to share the thoughts of professionals, scholars and academicians throughout the world.

\section{ABC Publications (ABC Journals)}

- Asian Accounting and Auditing Advancement (4A Journal)

- Asian Business Review (ABR)

- Asian Journal of Applied Sciences and Engineering (AJASE)

- Global Disclosure of Economics and Business (GDEB)

- $\quad$ ABC Journal of Advanced Research (ABC-JAR)

- International Journal of Reciprocal Symmetry and Theoretical Physics (IJRSTP)

- American Journal of Trade and Policy (AJTP)

- Asian Journal of Humanity, Art and Literature (AJHAL)

- Malaysian Journal of Medical and Biological Research (MJMBR)

- Asia Pacific Journal of Energy and Environment (APJEE)

- $\quad$ Engineering International (EI)

- $\quad$ ABC Research Alert (Online)

Each journal home page provides specific information for potential authors and subscribers. Open access policy, the quick review process, rich editorial boards and quality publications have already made $A B C$ Journals unique. ABC Journals are published under the direct supervisions of renowned academicians of the world.

Collaboration in Conference: $\mathrm{ABC}$ considers high-quality conference papers for publication. Please contact us for detailed information.

Collaboration in Publishing: If you like to start writing a book, propose a new journal or advertise in $\mathrm{ABC}$ journals, please feel free to contact us. 